\title{
POLÍTICAS DE HABITAÇÃO COMPARATIVAS: SIMULAÇÕES COM MERCADOS ENDÓGENOS'
}

Bernardo Alves Furtado²

\section{SINOPSE}

Este texto apresenta de forma breve os resultados do projeto modelos dinâmicos de simulaçáo, o qual envolve a modelagem de famílias, empresas e governos municipais, a partir de dados censitários, que interagem em vários mercados para investigar efeitos de alternativas de políticas públicas. A simulação foi realizada por meio de investimentos municipais endógenos em três políticas distintas para famílias com menor renda: i) subsídio de imóveis; ii) subsídio ao aluguel; e iii) auxílio monetário. As três foram comparadas com o caso-padrão, iv) sem investimentos. Vários indicadores sugerem que as políticas ii e iii apresentam melhor desempenho em termos de ganhos de consumo e produçáo (com reduçáo da desigualdade) em relação aos dois outros casos.

Palavras-chave: simulações; modelos baseados em agentes; política habitacional; políticas públicas; regióes metropolitanas.

Do ponto de vista do gestor público, uma pergunta relevante de política pública pode ser descrita como: dada uma quantidade fixa de recursos financeiros, qual investimento potencialmente traz mais benefícios sociais? Nesse sentido, em termos relativos e a partir de determinado conjunto de opçóes, simulaçóes de efeitos de políticas podem ser comparadas. Neste artigo, avaliamos, em uma simulação, duas alternativas de políticas de habitação e uma de auxílio financeiro, para, então, compararmos as três com resultados para o caso sem política. Avaliadas do ponto de vista de incremento na produção geral e redução da desigualdade, as políticas de auxílio e subsídio ao aluguel parecem trazer retornos superiores às alternativas.

Políticas habitacionais são simultaneamente custosas e necessárias. Parcela significativa (6 milhões) dos 72 milhões de domicílios brasileiros são consideradas pelo governo federal como deficit habitacional, com precariedades associadas à construção em si, seu acesso a serviços, ou ao ônus excessivo da família com o aluguel, por exemplo. Nesse contexto, identificar possíveis efeitos de políticas alternativas é relevante para a compreensão de mecanismos do fenômeno, bem como de sua mitigação.

No intuito de simular efeitos cíclicos e endógenos no mercado imobiliário, montamos uma simulação computacional a partir da literatura de modelos baseados em agentes. Informaçóes referentes às famílias (localização, composição, qualificação educacional), às empresas, aos municípios, e também a dados de evolução demográfica são todas utilizadas para qualificar os agentes. Em seguida, os agentes interagem - seguindo regras oriundas da literatura - nos mercados de trabalho, de bens e serviços, e imobiliário. Com o modelo verificado e validado, as alternativas de políticas públicas são inseridas na simulação e os resultados relativos comparados.

Os testes de robustez incluíram a análise de quase 6 mil simulaçóes (sensibilidade) para 46 regióes metropolitanas (RMs). Adicionalmente, um teste com aprendizado de máquinas foi feito com combinaçôes de todos os parâmetros para 1 milhão de possibilidades. Quatro políticas alternativas foram testadas, considerando as famílias mais pobres como beneficiárias: i) compra de residência e transferência para as famílias; ii) subsídio

1. DOI: http://dx.doi.org/10.38116/radar66art5

2. Técnico de planejamento e pesquisa na Diretoria de Estudos e Políticas Setoriais de Inovação e Infraestrutura (Diset) do Ipea. E-mail: <bernardo.furtado@ ipea.gov.br>. 
ao aluguel pelo período de dois anos; iii) auxílio monetário; e iv) ausência de política, que é o caso-padrão para comparação. As políticas i e ii só foram permitidas para famílias sem domicílio próprio.

Os resultados sugerem que a política mais benéfica - do ponto de vista do gestor público, dado o mesmo volume de recursos e buscando, maior nível de produção, menor desigualdade, melhoria da capacidade de pagamento das famílias com redução de dívidas - é a distribuição de auxílio financeiro, em volume menor e a um número maior de famílias, em contraste com as outras alternativas (gráfico 1). Em termos estritamente habitacionais, a política de subsídio ao aluguel mostrou-se bem competitiva em relação à política de auxílio financeiro.

É notável que a política de transferência de residências às famílias apresente resultados muito piores que as outras alternativas, entre os vários indicadores utilizados. Nossa interpretação é que a contratação e compra de imóveis é custosa em termos de recursos por família, ao mesmo tempo em que imobiliza os recursos públicos. Alternativamente, as demais políticas (de auxílio ou subsídio ao aluguel) permitem a circulação de recursos por meio do consumo das famílias ou do recebimento dos locadores, de modo que o montante dispendido retorna à economia, especialmente no caso simulado, o qual considera efeitos endógenos de processos, entre várias facetas de política e diferentes mercados.

\section{GRÁFICO 1}

Comparação para diferentes testes de políticas - Brasília (2010-2020) ${ }^{1}$

$1 \mathrm{~A}$ - Consumo das famílias

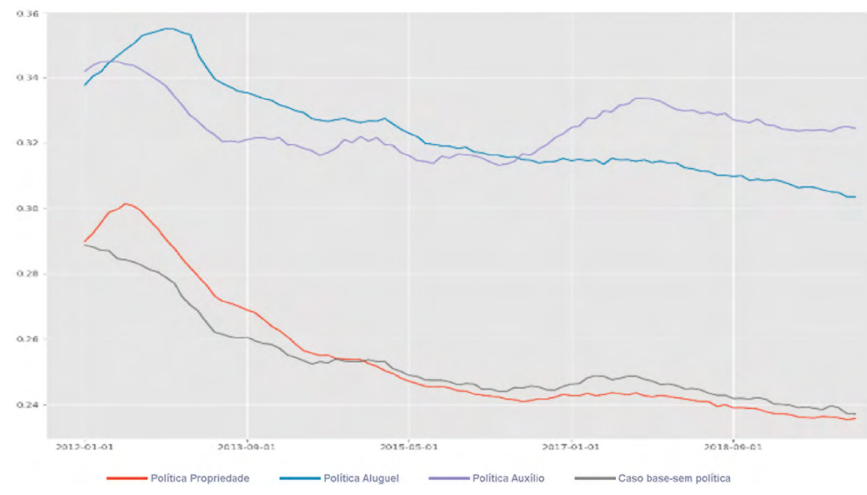

$1 \mathrm{C}-\mathrm{PIB}$

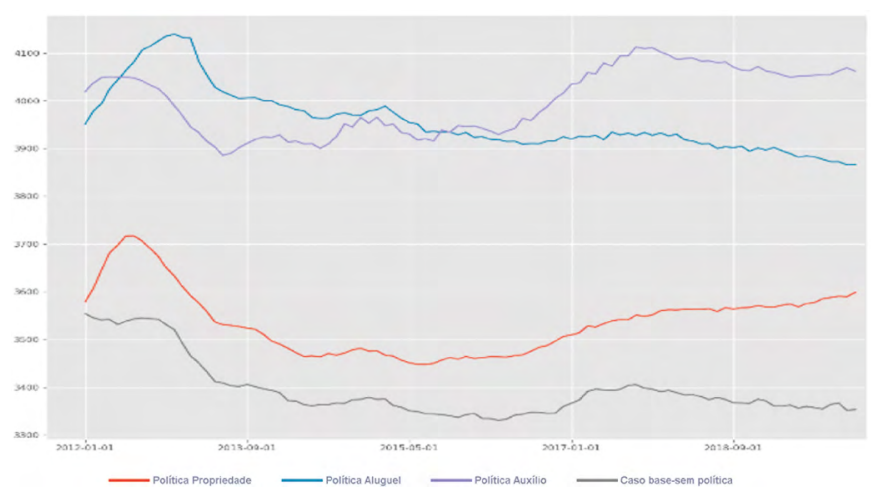

1B - Índice de preços

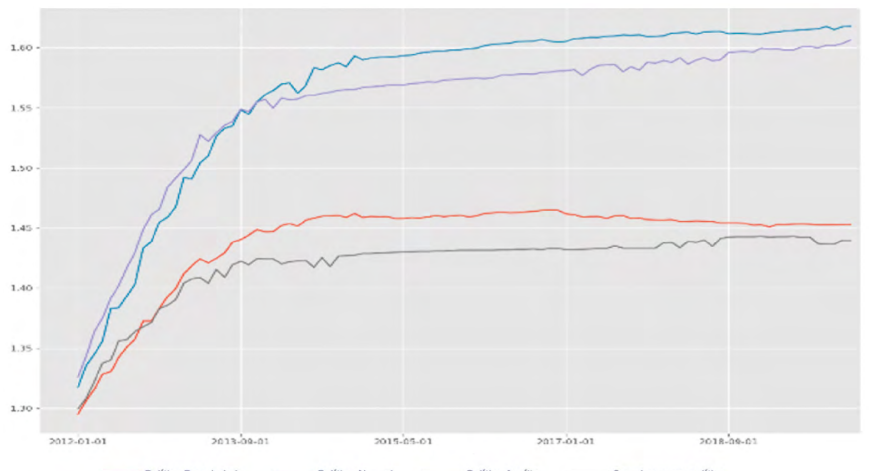

1D - Coeficiente de Gini

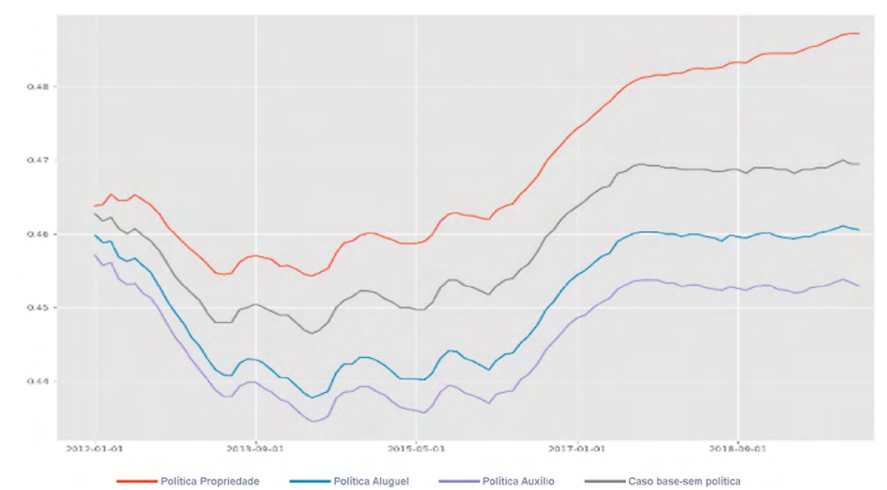

Elaboração do autor.

Nota: ${ }^{1}$ Média de vinte simulações por política para o caso-padrão.

Obs.: 1. Os resultados sugerem que a produção é maior e a desigualdade é menor quando implementadas as políticas de subsídio ao aluguel e ao auxílio monetário, se comparadas às outras duas alternativas. 0 consumo das famílias também é maior nesses dois casos, embora com custo de inflação em patamar ligeiramente superior.

2. Figuras cujos leiaute e textos não puderam ser padronizados e revisados em virtude das condições técnicas dos originais (nota do Editorial). 
As simulaçôes realizadas e a robustez dos resultados sugerem que a política de subsídio ao aluguel contém uma série de características que deveriam ser consideradas no momento de decisão acerca de políticas públicas habitacionais. Ao mesmo tempo que é mais flexível, permitindo maior mobilidade às famílias e adequação a alteraçóes no ciclo de vida ou de emprego, a política de subsídio permite atender um número maior de famílias em período de tempo mais curto. Por sua vez, o provimento de residências concentra recursos muito volumosos em uma quantidade pequena de beneficiários, ao mesmo tempo em que enrijece a inserção da família no tecido urbano em período de tempo prolongado.

Ainda assim, a contribuição das simulações parece ser na relevância da redução da desigualdade intraurbana e intrametropolitana quando utilizadas as políticas de subsídio ao aluguel ou auxílio financeiro direto às famílias.

Como trabalho futuro, vamos investigar os resultados de possíveis combinaçóes de políticas, com aplicação de percentuais de recursos em cada uma das alternativas, com auxílio de aprendizado de máquina. Assim, esperamos obter indicaçóes para percentuais ótimos de investimento em cada política e percentis de famílias a serem consideradas como beneficiárias, para RMs específicas.

\section{BIBLIOGRAFIA COMPLEMENTAR}

FURTADO, B. A. PolicySpace2: modeling markets and endogenous housing policies. ArXiv:2102.11929, 29 June 2021. Disponível em: <http://arxiv.org/abs/2102.11929>.

. PolicySpace2: modelando o mercado imobiliário e as políticas públicas. Brasília: Ipea, 2021. (No prelo). 